\title{
Viability of microencapsuls containing lactic acid bacteria under stimulated gastrointestinal conditions while incorporated in steamed rice cake
}

\begin{abstract}
The microencapsulation of Lactobacillus acidophilus NCIM2902 with alginate offers an effective means of delivery of viable bacterial cells in levels appropriate to the colon and helps in maintaining their survival during simulated gastric and intestinal juice. Nonencapsulated cells were completely destroyed when exposed to artificial gastric juice (AGJ) of $\mathrm{pH} 1.2$ after $2 \mathrm{~h}$ of incubation at $37^{\circ} \mathrm{C}$, while the treatment declined the viable count of encapsulated samples only by $4 \log$. Encapsulated cells exhibited a significantly higher resistance to artificial intestinal juice (AIJ) than non encapsulated samples. Sensory properties of SRC were improved by the addition of encapsulated L. acidophilus.
\end{abstract}

Keywords: Lactobacillus acidophilus, microencapsulation, AGJ, AIJ, HPLC, texture
Volume 3 Issue 2 - 2015

\author{
Arpita Das, Utpal Raychaudhuri, Runu \\ Chakraborty \\ Department of Food Technology and Biochemical Engineering, \\ Jadavpur University, India \\ Correspondence: Dr. Runu Chakraborty, Professor \\ Department of Food Technology and Biochemical \\ Engineering, Jadavpur University, Kolkata - 700032, India, Tel \\ +9103324|46822, Fax +9103324|46822, \\ Email crunu@hotmail.com
}

Received: October 30, 2015 | Published: December 19, 2015
Abbreviations: AGJ, artificial gastric juice, AIJ, artificial intestinal juice; $\mathrm{CFU}$, colony forming unit, HPLC, high performance liquid chromatography, LAB, lactic acid bacteria; SEM, scanning electron microscope; SRC, steamed rice cake

\section{Introduction}

Beneficial effects of probiotics on the human gut flora include antagonistic effects and immune effects. The use of probiotic bacterial cultures stimulates the growth of preferred microorganisms, crowds out potentially harmful bacteria and reinforces the body's natural defense mechanisms. ${ }^{1}$ Recently, probiotics have been proposed for various treatments of human intestinal barrier dysfunctions such as lactose intolerance, acute gastroenteritis, food allergy, atopic dermatitis, Crohn's disease, rheumatoid arthritis, and colon cancer. ${ }^{2,3}$ Such beneficial microorganisms have been added to various food stuffs to create "functional food or nutraceuticals." In order to exert positive health effects, lactic acid bacteria (LAB) have to resist gastric juice and bile salts. After the LAB pass through the stomach and upper intestinal tract, LAB should attach to the epithelium of the intestinal tract and grow. ${ }^{4}$ Providing probiotic living cells with a physical barrier against adverse environmental conditions is an approach currently receiving considerable interest. ${ }^{5}$ Studies have used cellulose acetate phthalate gelatin, vegetable gum, ${ }^{6}$ fats ${ }^{7}$ or $\kappa$-carrageenan ${ }^{8}$ as encapsulating agents, alginate remains the most commonly used bio polymer for microencapsulation. The advantages of using alginate as an encapsulating agent include: non-toxicity, formation of gentle matrices with calcium chloride to trap sensitive materials such as living microbial cells, simplicity in entrapping living microbial cells and low cost. Alginate is also an accepted food additive and can be safely used in food. ${ }^{8,9}$ It is indigestible for humans, and behaves much like a dietary fiber. ${ }^{10}$ Microencapsulation techniques have been successfully used to enhance dairy fermentation for the production of concentrated lactic acid bacteria ${ }^{11}$ and to improve the survival of microorganisms in dairy products, ${ }^{12}$ mayonnaise,,$^{13}$ and gastric juice, but till now no attempt has been made to fortify cooked product by utilizing microencapsulated
LAB. Therefore, this study was performed to determine the survival of encapsulated and free cells of $L$. acidophilus in steamed rice cake during exposure to artificial gastrointestinal juice and to evaluate their effect on the product quality.

\section{Materials \& methods}

\section{Preparation of encapsulated culture}

Lactobacillus acidophilus (NCIM 2902) was collected from culture collections of the National Collection of Industrial Microorganisms (NCIM), Pune, India. Microorganisms were grown at $37^{\circ} \mathrm{C}$ for $24 \mathrm{~h}$ in MRS broth (Himedia, India). Calcium alginate beads of immobilized cells were prepared according to the procedure of Sheu and Marshall. ${ }^{9}$ The beads were harvested by gentle centrifugation $(350 \times \mathrm{g}, 10 \mathrm{~min})$ and washed with sterile distilled water.

\section{Preparation of steamed rice cake (SRC)}

SRC were prepared with parboiled rice and split dehusked black gram dhal in 2:1 ratio. The ingredients, were washed and soaked separately for $4 \mathrm{~h}$ at $30 \pm 1^{\circ} \mathrm{C}$ and ground in a kitchen mixer blender separately, then both were mixed together with common salt $(2.0 \%)$. The combined mixture was then allowed to ferment for $20 \mathrm{~h}$ at $30 \pm 1^{\circ} \mathrm{C}$ in glass beakers covered with cotton cloths. One batch was the control (without L. acidophilus)and encapsulated and nonencapsulated L. acidophilus was added separately to the other two batches to give average initial concentrations of $1.2 \times 108 \mathrm{cfu} / \mathrm{ml}$ respectively. Test samples include preparation three types of samples, including without any microorganism designated as "A", non encapsulated microorganism enrichedSRC designated as "B", and encapsulated microorganism enriched SRC designated as " $\mathrm{C}$ ". While preparing $\mathrm{SRC}$, in case of encapsulated LAB, sodium alginate beads containing LAB were added and in case of non-encapsulated in SRC, same amount of LAB is added from MRS medium. The final product is obtained by cooking the fermented batter in a mould on steam for $20 \mathrm{~min}$. 


\section{Morphology and bacterial enumeration}

The morphology of the microcapsules was also examined by scanning electron microscope (SEM). The encapsulated samples were mount on the stub with the aid of double side tape and coated by sputter coater (Sputter Coater S150, Edwards, Germany) for 6min. Observations were made using the scanning electron microscope (FEI QUANT 200, Hillsboro, USA) at an accelerating voltage of $20.0 \mathrm{kV}$ Non-encapsulated L. acidophilus was enumerated in the MRS agar. Peptone water was used to prepare the serial dilutions and culture was plated by the pour plate technique. The plates were incubated at $37^{\circ} \mathrm{C}$ for $48 \mathrm{~h}$. To determine the viable counts of the encapsulated $L$. acidophilus, $0.1 \mathrm{~g}$ of capsules were resuspended in $10 \mathrm{ml}$ of phosphate buffer ( $\mathrm{pH}$ 7.4) and stirred for 30min using a magnetic stirrer. The colony forming units (CFU) were determined by aerobic plating on MRS agar plate and incubating at $37^{\circ} \mathrm{C}$ for $48 \mathrm{~h}$.

\section{Preparation of artificial gastric juice (AGJ) and artificial intestinal juice (AIJ)}

The AGJ was prepared with $\mathrm{pH}$ adjusted MRS broth which was adjusted to $1.2,2$ and 7.0 (control) with $5 \mathrm{~mol} / 1 \mathrm{HCl}$ or $1 \mathrm{~mol} / 1 \mathrm{NaOH}$ solution and sterilized. Suspending pepsin (1000 unit/ml) in MRS was sterile-filtered through a membrane filter $(0.45 \mu \mathrm{m}$, Lot No. BM6SM0117H, Millipore, Bengalore, India) and $0.1 \mathrm{ml}$ of suspending pepsin was inoculated to $9.9 \mathrm{ml}$ of AGJ. Three and $5 \mathrm{~g} / 1$ oxgall solutions were used as AIJ representing biles with 3 and $5 \mathrm{~g} / 1$ concentrations. The oxgall solutions were prepared by dissolving 0.03 and $0.05 \mathrm{~g}$ of oxgall in $10 \mathrm{ml}$ of MRS broth. All solutions were sterilized at $121^{\circ} \mathrm{C}$ for $15 \mathrm{~min}$

\section{Viability of probiotic microorganism in AGJ and AIJ}

The encapsulated L. Acidophilus beads from SRC sample and non-encapsulated L. acidophilus $(1.2 \times 108 \mathrm{cfu} / \mathrm{ml})$ samples of individual treatments were completely dispersed in $10 \mathrm{ml}$ of AGJ and AIJ. Nonencapsulated and encapsulated L. acidophilusin AGJ was incubated at $37 \mathrm{oC}$ and sampled every $60 \mathrm{~min}$. Sampled capsules in AGJ were neutralized with $\mathrm{NaOH}$ solution, and centrifuged at $2000 \times \mathrm{g}$ for $10 \mathrm{~min}$. The obtained capsules were resuspended in $10 \mathrm{ml}$ of phosphate buffer (pH 7.4) and viable cells of non-encapsulated and encapsulated L. Acidophilus was incubated in $37^{\circ} \mathrm{C}$ for $3 \mathrm{~h}$. Samples were taken hourly for determination of the cell count. An aliquot of $100 \mu 1$ was diluted $1 / 10$ and then serially diluted to obtain a sensible dilution for plating. The plates were incubated under anaerobic conditions at $37^{\circ} \mathrm{C}$ for $48 \mathrm{~h}$. To determine the viability in AIJ, samples were withdrawn after incubation at $37^{\circ} \mathrm{C}$ for $3 \mathrm{~h}$. Determination of cell count was done as described above.

\section{Physico-chemical analysis of SRC}

The total lactic acid concentration was determined by the technique described by Balasubramanian et al., ${ }^{14}$ Diacetyl production and hydrogen peroxide production was determined using a method described by Edema et al., ${ }^{15}$ The SPE method of Cho et al., ${ }^{16}$ was used for the extraction of water-soluble vitamins. A method given by Sreelatha et al., ${ }^{17}$ was used to detect the DPPH radical scavenging activity. SRC samples were coded and presented to 30 panel members for sensory scoring. Water was used for mouth rinsing before and after each sample testing. Samples were scored for appearance, taste, colour, texture, aroma and overall acceptability according to numerical scoring system. The model used in this analysis was an acceptance test on the hedonic scale, with values ranging from " 1 " (extremely disliked) to "9" (extremely liked).

\section{Results and discussion}

\section{Morphology}

The size and shape of the beads was determined from the electron photomicrographs, as well as by using the light microscope. The encapsulation procedure used in this study resulted in bead size of $1-1.4 \mathrm{~mm}$. Size segregation was carried out using 14-16 mesh size sieves. Figure 1 shows the shapes and surface morphologies of alginate capsule. The shape of the beads was generally spherical; sometimes elliptical shaped capsules were observed as well. There was a large variation in capsule size depending of the probiotic strain and prebiotic contents. The size of calcium alginate microencapsulation can be affected by various factors such as alginate concentration, probiotic cell load, and hardening time in calcium chloride etc. According to the morphological analysis of the freeze-dried microcapsule, they generally were spherical with a wrinkled surface and a collapsed centre containing bacteria (Figure 1). The wrinkled surface was probably due to the loss of water content during the freeze-drying process. ${ }^{18}$ Alginate microparticles usually had a heterogeneous structure with a dense surface layer and a loose core due to the heterogeneous gelation mechanism, which resulted in the collapsed center during the drying process. ${ }^{19}$

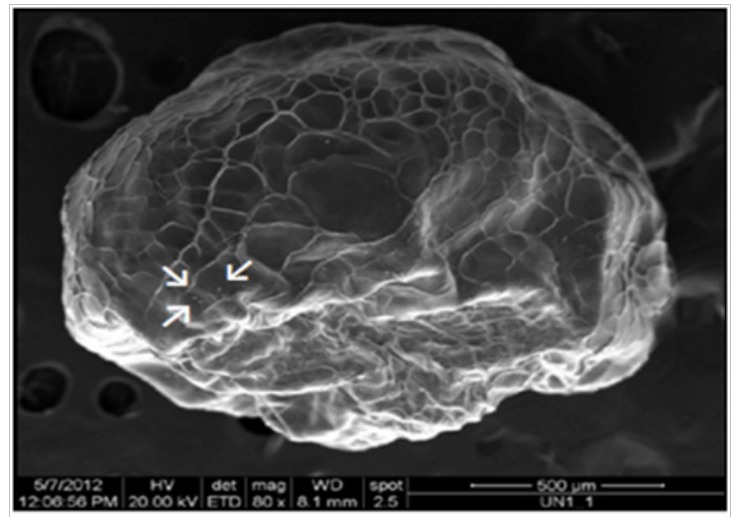

Figure I Micrograph of the microcapsule containing L. acidophilus (NCIM 2902) encapsulated in alginate with entrapped bacteria (arrows).

\section{Viability of L. acidophilus(NCIM 2902) in AGJ}

To be used as probiotics, bifidobacteria must survive the transit through the stomach to be able to reach the intestine. ${ }^{20}$ In order to determine the influence of the $\mathrm{pH}$ on the survival of non-encapsulated and encapsulated L. acidophilus, in vitro system was used. According to Berrada et al., ${ }^{21}$ for the acidity resistance, there was only a slight difference between in vitro and in vivo results. When inoculated in AGJ at $\mathrm{pH} 1.2$ at $37^{\circ} \mathrm{C}$ a dramatic decline in non-encapsulated $L$. acidophilus was observed $5 \log$ reduction after $1 \mathrm{~h}$ and complete destruction after $3 \mathrm{~h}$. On the other hand, encapsulated L. acidophilus in AGJ maintained above $104 \mathrm{cfu} / \mathrm{ml}$ at $\mathrm{pH} 1.2$ after $3 \mathrm{~h}$ (Figure 2). At $\mathrm{pH}$ 2, non-encapsulated L. acidophilus decreased from $1.1 \times 1010$ to $16 \mathrm{cfu} / \mathrm{ml}$ after $3 \mathrm{~h}$ of incubation while encapsulated L. acidophilus decreased from $1.1 \times 1010$ to $9 \times 105 \mathrm{cfu} / \mathrm{ml}$. At $\mathrm{pH} 7.0$ (control), viability of L. acidophilus in AGJ remained almost constant after $3 \mathrm{~h}$ incubation at $37^{\circ} \mathrm{C}$ whether encapsulated or not. SEM micrograph of the microcapsule containing L. acidophilus after $3 \mathrm{~h}$ incubation in artificial gastric conditions is shown in Figure 3. For lactic acid bacteria to exert positive health effects, they have to colonize on the colon in large quantities. ${ }^{22}$ Free L. acidophilus was very feeble in the low-pH environment. This is in good agreement with the similar 
study done by Rao et al., ${ }^{23}$ who reported that no Bifidobacterium pseudolongum survived in the simulated gastric environment of $\mathrm{pH} 1.33$ for $60 \mathrm{~min}$, but at $\mathrm{pH} 6.06$ and 7.13 survival was fully sustained. Sheu et al., ${ }^{12}$ reported that calcium alginate could provide good protection $(90 \%)$ for lactobacilli in frozen ice milk. FavaroTrindale and Grosso ${ }^{24}$ showed that none of L. acidophilus (La-05) survived in the artificial gastric environment of $\mathrm{pH} 1.0$ after $1 \mathrm{~h}$, but microencapsulated L. acidophilus (La-05) suffered a reduction of $1 \log$ at $\mathrm{pH} 1.0$ after $2 \mathrm{~h}$ incubation. According to Chandramouli et al., ${ }^{4}$ a higher survival of L. acidophilus CSCC2400 and CSCC2409 immobilized in alginate bead in low $\mathrm{pH}$ environments. Our results suggested that non-encapsulated $L$. acidophilus was sensitive to the acidic environment ( $\mathrm{pH} 1.2$ and 2) and the ingestion of unprotected lactic acid bacteria might result in reduced viability. Therefore, the survival of encapsulated L. acidophilus in the gastric environment was significantly $(\mathrm{P} \leq 0.05)$ better than that of non-encapsulated $L$. acidophilus. This indicates that the product with encapsulated cells, which initially contained $1.2 \times 1010 \mathrm{cfu} / \mathrm{ml}$, could reach the small intestine with a good probiotic concentration $(9 \times 107 \mathrm{cfu} / \mathrm{ml})$ at $\mathrm{pH} 7$.

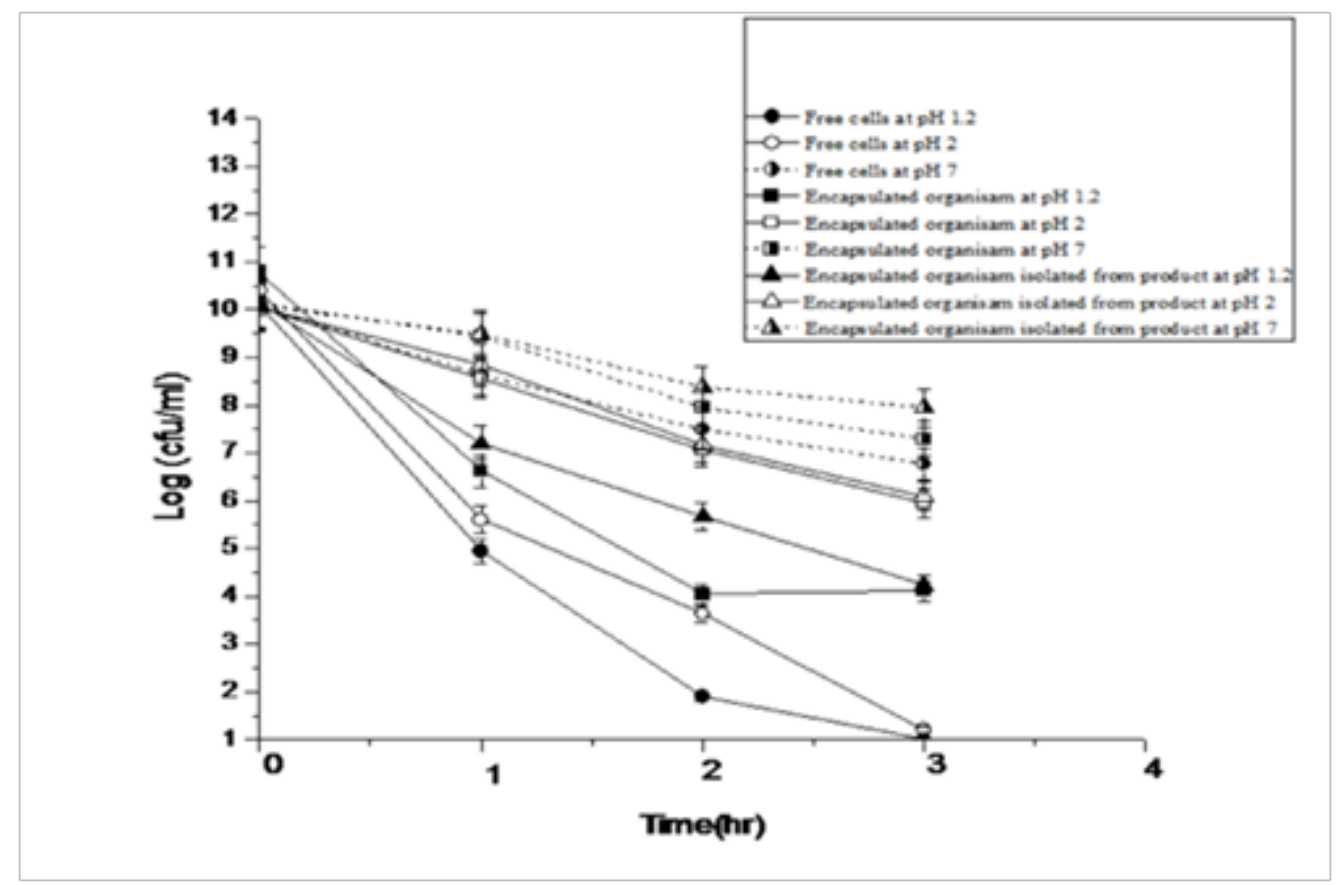

Figure 2 Survival of non-encapsulated, encapsulated and encapsulated organism isolated from the product L. acidophilus NCIM 2902 after sequential incubation in artificial gastric conditions.

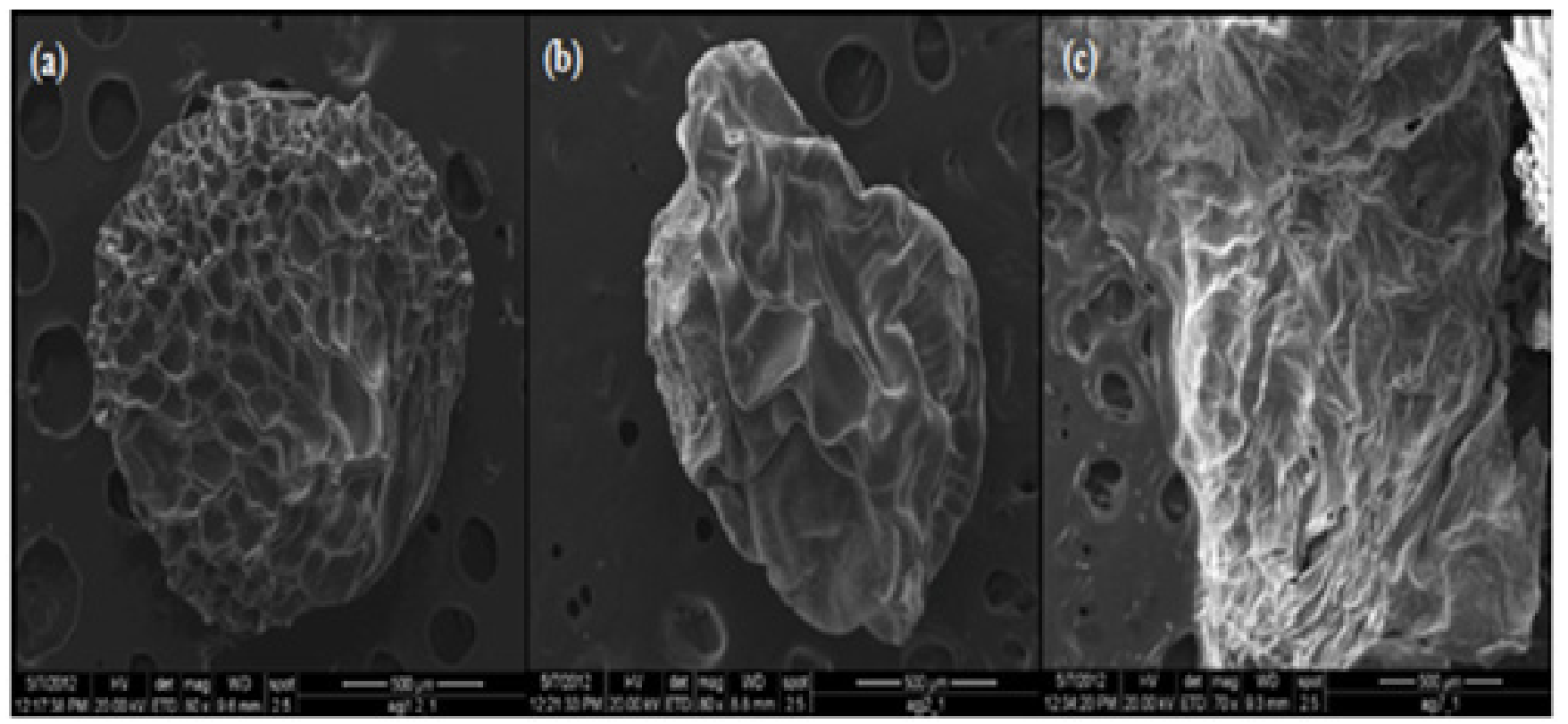

Figure 3 SEM micrograph of the microcapsule containing L. acidophilus: after 3 h incubation in artificial gastric conditions (A) pH I.2 (B) pH 2 (C) pH 7. 


\section{Viability of L. acidophilus(NCIM 2902) in AlJ}

Chou \& Weimer $^{25}$ reported that in order for LAB to exert positive health effects, they should resist the stressful conditions of the stomach and upper intestine that contain bile. According to Mituoka ${ }^{26}$ L. acidophilus is most active in the small intestine and $B$. bifidum is most active in the large intestine of humans. Therefore, $L$. acidophilus should resist bile acid. Survivals of non-encapsulated and encapsulated L. acidophilus were monitored up to $6 \mathrm{~h}$ after exposure to $0.3 \%$ and $0.5 \%$ AIJ (Figure 4 ). The viability of non-encapsulated L. acidophilus decreased from $1.2 \times 1010$ to $8 \times 105$ and from $1.3 \times 1010$ to $5 \times 104$, respectively, at $0.3 \%$ and $0.5 \%$ bile concentration after $6 \mathrm{~h}$ incubation at $37^{\circ} \mathrm{C}$. However, the viabilities of encapsulated and encapsulated organism isolated from final product, L. acidophilus were not decreased significantly at $0.3 \%$ and $0.5 \%$ AIJ after $6 \mathrm{~h}$. Initial cell numbers of $L$. acidophilus in alginate microparticles dropped from $1.4 \times 1010$ to $2 \times 105 \mathrm{cfu} / \mathrm{ml}$ and initial cell numbers of $L$. acidophilus in encapsulated organism isolated from final product dropped from $1.3 \times 1010$ to $3 \times 106 \mathrm{cfu} / \mathrm{ml}$ in $0.5 \%$ bile concentration after $6 \mathrm{~h}$ incubation at $37^{\circ} \mathrm{C}$. SEM micrograph of the microcapsule containing L. acidophilus after $3 \mathrm{~h}$ incubation in artificial intestinal conditions is shown in Figure 5. The present results agreed with previous reports ${ }^{27}$ that acid and bile resistance of free cells varies greatly among strains within a species and among species. Microencapsulation of various bacterial cultures including probiotics has been a common practice for expanding their shelf life. ${ }^{8}$ It has been reported that $L$. acidophilus was significantly better with regard to bile tolerance than other cultures. ${ }^{28,29}$ Our study demonstrated microcapsulation using alginate may be an effective way to increase the survival of L. acidophilus in bile solution. Sultana et al., ${ }^{22}$ also reported similar type of results.

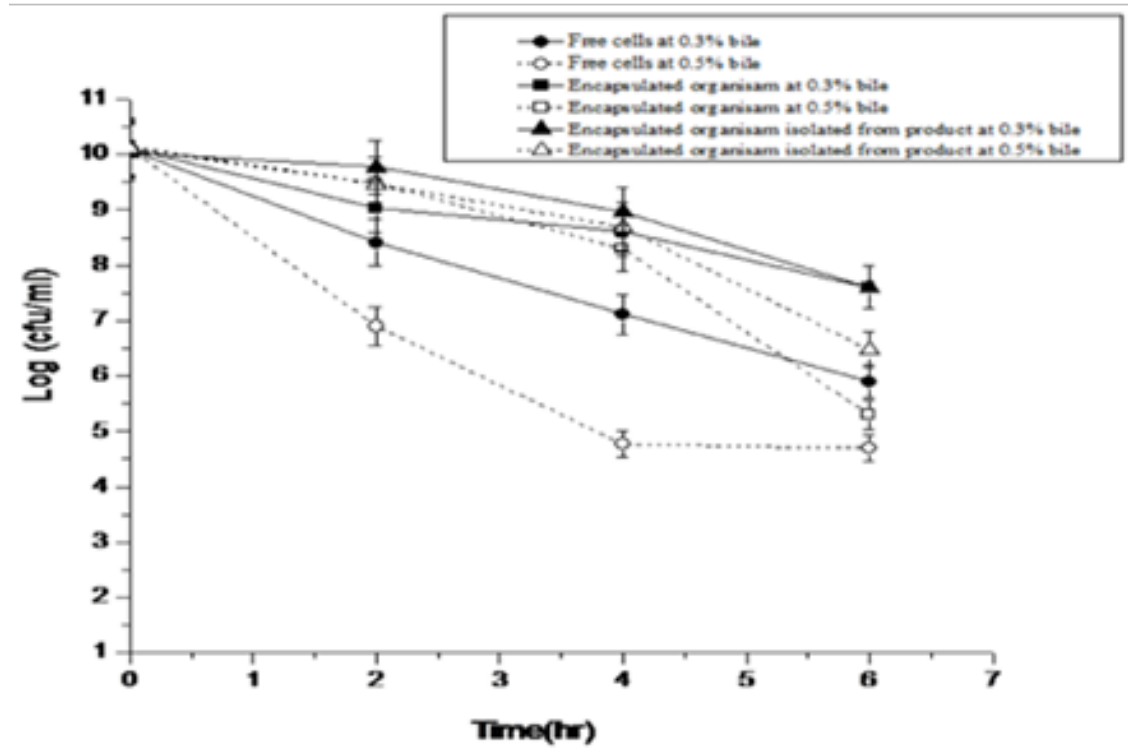

Figure 4 Survival of non-encapsulated, encapsulated and encapsulated organism isolated from the product L.Acidophilus NCIM 2902 after sequential incubation in artificial intestinal conditions.

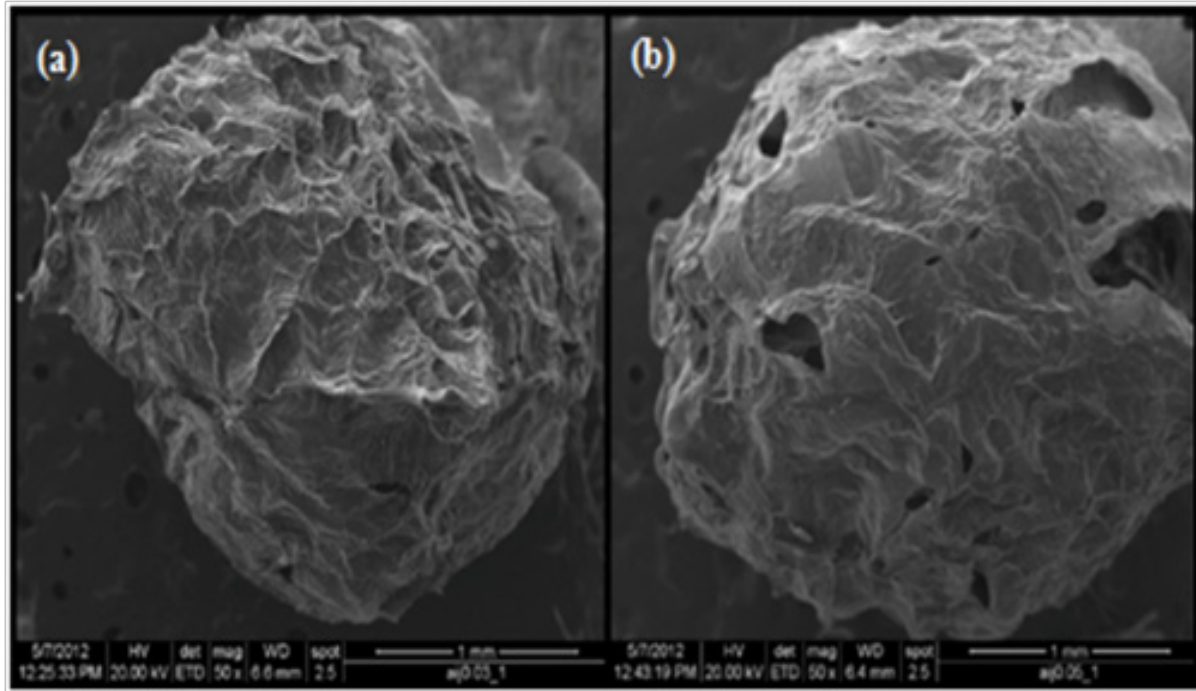

Figure 5 SEM micrograph of the microcapsule containing L. acidophilus: after $3 \mathrm{~h}$ incubation in artificial intestinal conditions (A) $0.03 \%$ bile solution (B) $0.05 \%$ bile solution. 


\section{Physico-chemical analysis of SRCsamples}

Total lactic acid concentration and $\mathrm{pH}$ ofSRC batter was affected significantly $(\mathrm{p} \leq 0.05)$ by free and encapsulated L. acidophilus. SRC batter containing encapsulated $L$. acidophilus had highest $(\mathrm{P} \leq 0.05)$ diacetyl and hydrogen peroxide values than those of controls and samples containing free cells of $L$. acidophilus. SRC containing encapsulated L. acidophilus had highest $(\mathrm{P} \leq 0.05)$ antioxidant potential than those of controls and samples containing free cells of $L$. acidophilus. The concentration of water-soluble vitamin such as panthothenic acid (vitamin B5), thiamine (vitamin B1) and folic acid (vitamin B9) at 20h after fermentation in different test samples is shown in Table 1. It is evident from Table 1 that sample $\mathrm{C}$ provides maximum production of all vitamins. Sensory data of the test, texture and overall acceptability of different SRC samples were presented (Table 1) at significant difference level $p \leq 0.05$. The increase in total acidity could be attributed to acid production by surviving lactic acid bacteria. The $\mathrm{pH}$ value of SRC batter containing encapsulated lactic acid bacteria was lower $(\mathrm{P} \leq .05)$ than other treatments. LAB have been known to take part in bread fermentations such as in the production of the Swedish rye sourdough ${ }^{30}$ and the IndianIdli ${ }^{31}$ wherein they improve flavor, texture and keeping quality through the production of metabolites such as diacetyl, hydrogen peroxide and bacteriocins, these compound give fermented food their characteristic flavor and also impart improved safety and rheology to the food. The increase in antioxidant potential could be attributed by surviving LAB. Ghosh et al., ${ }^{32}$ found enhanced amount of vitamin B production during fermentation and $7 \mathrm{~h}$ is the recommended time for the production of maximum amount of B vitamins, possibly because they use $L$. mesenteroides, whereas in our study the organisms involved was $L$. acidophilus. On the taste aspect of the SRCsamples, SRC containing encapsulated L. acidophilus scored the highest appreciation, followed by the samples containing free cells of $L$. acidophilus. The control which is without any $\mathrm{LAB}$ scored lowest score as it does not content characteristic sour aroma produced by LAB. Texture of the SRC containing encapsulated L. acidophilus showed lowest score as it contain alginate beads incorporated in it. In terms of overall acceptability index, SRC containing encapsulated L. acidophilus was credited to be superior to both control and samples containing free cells of $L$. acidophilus.

Table I Physico-chemical characteristics of steamed rice cake samples

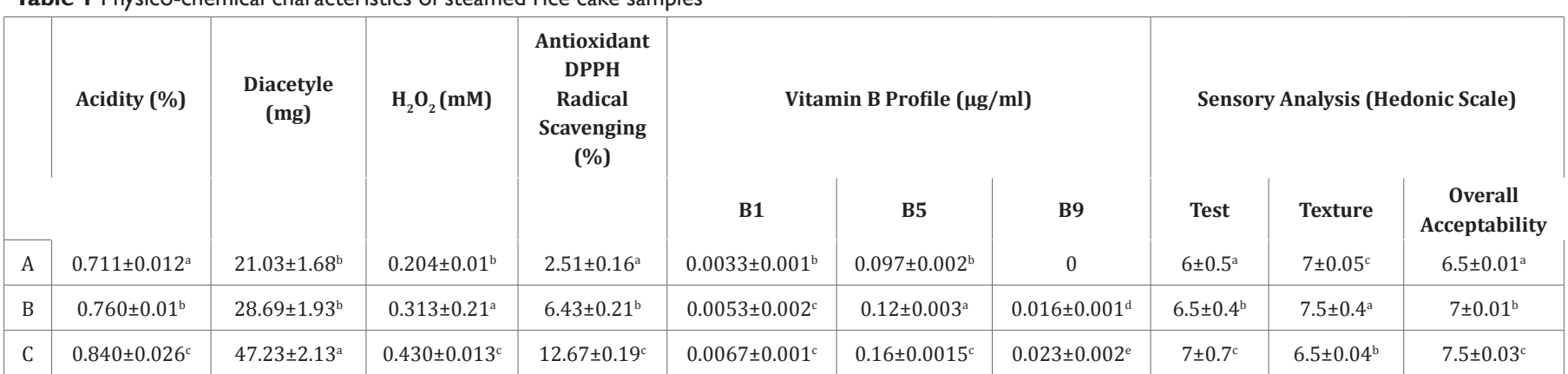

Test samples include preparation three types of samples, including without any microorganism designated as " $A$ ", non encapsulated microorganism enriched SRCdesignated as " $B$ ", and encapsulated microorganism enrichedSRC designated as " $C$ ". Values are Mean $\pm S D, n=3$. Mean values followed by different letters within columns are significantly different by Fisher's LSD tests at $p \leq 0.05$

\section{Conclusion}

Microencapsulation offers significant benefits to food technology and production. It provides a solution to the low viability of probiotics incorporated in food products. Ideally it can maintain the level of the beneficial probiotic bacteria at the minimum standard amount required. One of the requirements for microorganisms to be used as dietary adjuncts is the need to maintain viability and activity in the carrier food before consumption. Microencapsulation in alginate microparticles successfully improved the survival of L. acidophilus in AGJ and AIJ. A good quality SRC could be manufactured by incorporating encapsulated L. acidophilus NCIM 2902 in calcium alginate beads. Furthermore, the sensory evaluation of SRC with microencapsulated probiotic bacteria has revealed the consumer response, to the texture and the changes in organo-leptic characteristic of the steamed rice cake.

\section{Acknowledgements}

This research work is financially supported by the Centre for Advanced Studies (CAS I) programme under University Grants Commission (UGC), India.

\section{Conflict of interest}

The manuscript represents original work that is not being considered for publication, in whole or in part, in another journal, book, conference proceedings, or government publication with a substantial circulation and there is no conflict of interest.

\section{References}

1. Kalliomaki M, Salminen S, Poussa T, et al. Probiotics and prevention of atopic disease: 4-year follow-up of a randomised placebo-controlled trial. Lancet. 2003;361(9372):1869-1871.

2. Lee YK, Puong KY, Ouwehand AC, et al. Displacement of bacterial pathogens from mucus and Caco-2 cell surface by Lactobacilli. J Med Microbiol. 2003;52(Pt 10):925-930.

3. Chandramouli V, Kailasapathy K, Peiris P, et al .An improved method of microencapsulation and its evaluation to protect Lactobacillus spp. in simulated gastric conditions. J Microbiol Methods. 2004;56(1):27-35.

4. Doleyres Y, Lacroix C. Technologies with free and immobilised cells for probiotic bifidobacteria production and protection. Int Dairy J. 2005;15(10):973-988.

5. Shah NP. Probiotic bacteria: selective enumeration and survival in dairy foods. J Dairy Sci. 2000;83(4):894-907.

6. Siuta-Cruce P, Goulet J. Improving probiotic survival rates: microencapsulation preserves the potency of probiotic micro-organisms in food systems. Food Technol. 2001;55:37-39.

7. Krasaekoopt W, Bhandari B, Deeth H. Evaluation of encapsulation techniques of probiotics for yoghurt. Int Dairy J. 2003;13(1):3-13. 
8. Sheu TY, Marshall RT. Microentrapment of lactobacilli in calcium alginate gels. J Food Sci. 1993;58(3):557-561.

9. Brownlee IA, Allen A, Pearson JP, et al. Alginate as a source of dietary fiber. Crit Rev Food Sci. 2005;45(6):497-510.

10. Dembczynski R, Jankowski T. Growth characteristics and acidifying activity of Lactobacillus rhamnosusin alginate/starch liquid-core capsules. Enzyme Microb Technol. 2002;31(1-2):111-115.

11. Sheu TY, Marshall RT, Heymann H. Improving survival of culture bacteria in frozen desserts by microentrapment. $J$ Dairy Sci. 1993;76(7):1902-1907.

12. Khalil AH, Mansour EH. Alginate encapsulated Bifidobacteria survival in mayonnaise. J Food Sci. 1998;63(4):702-705.

13. Balasubramanian S, Viswanathan R. Properties of idli batter during its fermentation time. J Food Process Preserv. 2007;31(1):32-40.

14. Edema MO, Sanni AI. Functional properties of selected starter cultures for sour maize bread. Food Microbiol. 2008;25(4):616-625.

15. Cho CM, Ko JH, Cheong WJ. Simultaneous determination of watersoluble vitamins excreted in human urine after eating an overdose of vitamin pills by a HPLC method coupled with a solid phase extraction. Talanta. 2000;51(4):7998-7906.

16. Sreelatha S,Padma PR. Antioxidant Activity and Total Phenolic Content of Moringa oleifera Leaves in Two Stages of Maturity. Plant Foods Hum Nutr. 2009;64(4):303-311.

17. Kwok KK, Groves MJ, Burgess DJ. Production of 5-15 $\mu \mathrm{m}$ diameter alginate polylysine microcapsules by an air atomization technique. Pharm Res. 1991;8(3):341-344.

18. Skjåk-Bræk G, Grasdalen $\mathrm{KH}$, Draget KI, et al. Inhomogeneous polysaccharide ionic gels. Carbohydr Polym. 1989;10(1):31-54.

19. Lian WC, Hsao HC, Chou C. Viability of microencapsulated bifidobacteria in simulated gastric juice and bile solution. Int $J$ Food Microbiol. 2003;86(3):293-301.

20. Berrada N, Lemeland JF, Laroche G, et al. Bifidobacterium from fermented milks: Survival during gastric transit. J Dairy Sci. 1991;74(2):409-413.
21. Sultana K, Godward G, Reynolds N, et al. Encapsulation of probiotic bacteria with alginate-starch and evaluation of survival in simulated gastrointestinal conditions and in yoghurt. Int $J$ Food Microbiol. 2000;62(1-2):47-55.

22. Rao AV, Shiwnavain N, Maharaj I. Survival of microencapsulated Bifidobacterium pseudolongum in simulated gastric and intestinal juices. Can Inst Food Sci Technol. 1989;22(4):345-349.

23. Favaro-Trindale CS, Grosso CR. Microencapsulation of L. acidophilus (La-05) and $\mathrm{B}$. lactis (Bb-12) and evaluation of their survival at the $\mathrm{pH}$ values of the stomach and in bile. J Microencapsul. 2002;19(4):485-494.

24. Chou LS, Weimer B. Isolation and characterization of acid- and biletolerant isolates from strains of Lactobacillus acidophilus. J Dairy Sci. 1999;82(1):23-31.

25. Mituoka T. The human gastrointestinal tract. In: Wood BJB, editors. The lactic acid bacteria in health and disease. London, NY: Elsevier Applied Science; 1992

26. Hansen LT, Allan-Wojtas PM, Jin YL, et al. Survival of Ca-alginate microencapsulated Bifidobacterium sppin milk and simulated gastrointestinal conditions. Food Microbiol. 2002;19(1):35-45.

27. Buck LM, Gilliland SE. Comparisons of freshly isolated strains of Lactobacillus acidophilus of human intestinal origin for ability to assimilate cholesterol during growth. $J$ Dairy Sci. 1994;77(10):2925-2933.

28. Gilliland SE, Walker DK. Factors to consider when selecting a culture of Lactobacillus acidophilus as a dietary adjunct to produce a hypocholesterolemic effect in humans. J Dairy Sci. 1990;73(4):905-911.

29. Lonner C, Preve-Akesson K. Acidification properties of lactic acid bacteria in rye sour doughs. Food Microbiol. 1988;5(1):43-58.

30. Mukherjee SK, Albury MN, Pederson CS, et al. Role of Leuconostoc mesenteroides in leavening the batter of idli, a fermented food of India. Appl Microbiol. 1965;13:227-231.

31. Ghosh D, Chattopadhyay P. Preparation of idli batter, its properties and nutritional improvement during fermentation. J Food Sci Technol. 2010;48(5):610-615

32. Lonner C, Preve-Akesson K. Acidification properties of lactic acid bacteria in rye sour doughs. Food Microbiol. 1988;5(1):43-58. 